\title{
The geography of body size in cuttlefishes (Cephalopoda, Sepiidae)
}

\author{
Pascal Neige* (1)
}

\begin{abstract}
This study explores body size in sepiids (Cephalopoda, Sepiidae) on the interspecific scale and provides an overview of their geographical distribution. Results reveal a highly skewed distribution of body size variation for raw values and a nearly normal distribution for log-transformed data. However, normality is not statistically validated due to the overrepresentation of small and large species. The geographical distribution of sepiids reveals five main clusters: Atlantic, Cape Basin, Indian Ocean, Asia-Pacific, and Australian. On average, clusters display more or less the same mean body size pattern except the Cape Basin cluster, which is statistically different from the others (smaller interspecific mean body size). The reasons remain unclear but a phylogenetic effect is suspected as southwest African coastal waters concentrate species from the 'Hemisepius' complex which is made up of small species. Sepiids do not obey Bergmann's rule: species from high latitudes do not tend to be larger than species from low latitudes.
\end{abstract}

Keywords: Body size, Biogeography, Bergmann's rule, Coleoidea, Sepiidae

\section{Introduction}

Sepiidae (cuttlefishes) are a speciose family of cephalopods with a wide variety of forms classified in the genera Sepia Linnaeus 1758, Sepiella Gray 1849, and Metasepia Hoyle 1885. They belong to the Order of Sepiida, which is included in the Subclass Coleoidea. The monophyly of the Family Sepiidae admits no doubt (see Allcock et al., 2015; Carlini, 2010 for an overview of phylogeny within coleoids and cephalopods, respectively), based on both molecular and anatomical analyses. However, phylogenetic relationships within the sepiids are far from wellestablished (Allcock et al., 2015; Bonnaud et al., 2006; Yoshida et al., 2010). Members of the order Sepiida (Sepiidae, Belosaepiidae or Belosepiellidae) are rarely fossilized, but apart from the rare findings of cuttlebone remains, fossil statoliths have been recently published (Neige et al., 2016) suggesting an evolutionary radiation

Editorial handling: Christian Klug.

${ }^{*}$ Correspondence: pascal.neige@u-bourgogne.fr

Biogéosciences, UMR CNRS 6282, Université Bourgogne Franche-Comté, 6 Boulevard Gabriel, 21000 Dijon, France of the Order Sepiida dated from 46 to $42 \mathrm{Ma}$ (Neige et al., 2016).

Sepiids are known from the "Old World" only (Khromov, 1998; Neige, 2003; Nesis, 1987; Reid et al., 2005). Most sepiid cuttlefishes live in coastal waters, and although they are bottom dwellers, they are excellent swimmers when they leave the sea floor. Sepiid bathymetric distribution ranges from the sea surface down to $1000 \mathrm{~m}$ (Sepia hedleyi, according to Reid et al., 2005) but invariably in proximity to the continental shelf or upper slope (Khromov, 1998). They spawn medium-sized eggs fixed to a substratum (Boletzky, 1998). No planktonic stages exist for young animals (Young et al., 1998), and because they need to stay close to the bottom, they cannot cross deep oceans. Their lifespan is between 18 and 24 months (Reid et al., 2005). They possess a unique anatomical feature among living cephalopods: the dorsally embedded aragonitic shell known as the cuttlebone (or sepion) that is involved in buoyancy control (Denton \& Gilpin-Brown, 1961a, b) and displays large shape differences across species (Bonnaud et al., 2006; Lu, 1998a; Neige, 2003). Together with cuttlebone shape, differences among species also occur for various anatomical 
characters, such as sucker arrangement on arms or tentacular club anatomy.

Body size also appears to be a differentiating trait among sepiid species. Sepia dubia, one of the smallest cuttlefishes, does not exceed $3 \mathrm{~cm}$ in total (see Lipinski \& Leslie, 2018, Figure 28), whereas the Australian giant cuttlefish (Sepia apama) reaches a meter in length and may weigh more than ten kilograms for the largest individuals (see Reid, 2016a for a complete description of this species). An organism's "body size" is frequently viewed as one of its most basic features (Blackburn \& Gaston, 1994). It reflects phylogenetic constraints (i.e., the body size of an organism mainly depends on a genetic control) together with growth conditions (e.g., food supply). When studied at a local scale, the body size of an organism within a population may reflect ecology (e.g., temperature): organisms of a single species may have different body sizes depending on their environmental life conditions. Conversely, at a broader scale, the body-size pattern may help to explain a number of observed diversity patterns given that body size is related to abundance or geographic range size, for example. Consequently, body size variation is of essential concern to macroecology, whether working on living (Berke et al., 2013; Chown \& Gaston, 2010; Torres-Romero et al., 2016) or extinct (Dommergues et al., 2002; Jablonski, 1997; O'Gorman \& Hone, 2012; Smith et al., 2016) organisms. One way to explore size patterns is to document the shape of the frequency distribution of species body size. It appears fundamental (Blackburn \& Gaston, 1994) and useful for exploring various aspects at the interspecific level (e.g., the relationship between body size and latitude) and for converting these results into ecogeographic rules (Gaston et al., 2008), which are of particular interest to an understanding of shape biodiversity. Given the present biodiversity crisis, exploring these patterns is critically important for predicting how biodiversity may be affected by global change and for identifying reliable actions to preserve it.

Body size variations are well-known for a large number of cuttlefish species (e.g., those of fishery value). For example it is common knowledge that Sepia officinalis reaches different adult sizes depending on geography (Guerra et al., 2015; Neige \& Boletzky, 1997), or that Sepia orbignyana displays different adult sizes for males and females (Reid et al., 2005). However, at the interspecific scale, it seems that nothing is well-known! This can be illustrated by two examples. The monograph published by Adam \& Rees (1966) is a masterpiece, which can be considered as the first modern synthesis of the family Sepiidae. The authors provide a critical revision of all recent species and discuss various aspects of their systematic evolutionary history and geographical and bathymetric distribution. Specimens' mantle lengths are given for each species, sometimes with details about sexual dimorphism, but no data or discussion is published for body size at the interspecific scale. The monograph published by Reid et al. (2005) is the most recent impressive synthetic publication, which lists and details various aspects including informative body size data for most recent species. However, the only quantitative datum about interspecific body size variations is the maximum body size observed for the whole clade ("Up to $500 \mathrm{~mm}$ mantle length, and $12 \mathrm{~kg}$ in weight"), and the only qualitative information given is that sepiids are "small to medium-sized cephalopods".

The present study focuses on interspecific variations of body size within the family Sepiidae and their relationships with geography. It aims to establish and explore an initial set of data. Among the different ecogeographic rules discussed in the literature, evidence for Bergmann's rule is sought. Although controversial (Meiri \& Dayan, 2003), a myriad of publications discuss it based on many different taxa, including endotherms and ectotherms, the latter being the case of sepiids (Berke et al., 2013; Mousseau, 1997; Van Voorhies, 1996; Vinarski, 2014). In a synthetic formulation applicable to interspecific studies (see Blackburn et al., 1999), Bergmann's rule states that species from cooler climates (or high latitudes or altitudes, shallow-water bathymetry) tend to be larger than those from warmer climates (or low latitudes or altitudes, deep-water bathymetry). Reasons for such a pattern remain largely unknown (see Blackburn et al., 1999). Traditionally, the main reason given is that high latitudes favor large body sizes, because large body sizes increase heat retention (because of higher surface area to volume ratios). Finally, and as this study is a preliminary survey focusing on interspecific body size variations, it will also provide caveats that should be considered for further investigations.

\section{Materials and methods \\ A database of cuttlefish body size and geography}

The present analysis is based on an up-to-date bibliographic compilation of sepiid body sizes at the species level and so can be used for interspecific comparisons.

Selected species are those generally recognized as valid species by sepiid workers (e.g., Adam \& Rees, 1966; Khromov et al., 1998; Lu, 1998b; Reid, 2000; Reid et al., 2005; Roper et al., 1984). Recent taxonomic publications have also been considered (e.g., Ho \& Lu, 2005; Lipinski \& Leslie, 2018; Mqoqi et al., 2007; Neethiselvan \& Venkataramani, 2010; Reid, 2016a). In total 116 species are selected (Table 1) from the World Register of Marine Species (WoRMS Editorial Board, 2021). They belong to three genera (Sepia, Sepiella, and Metasepia, 


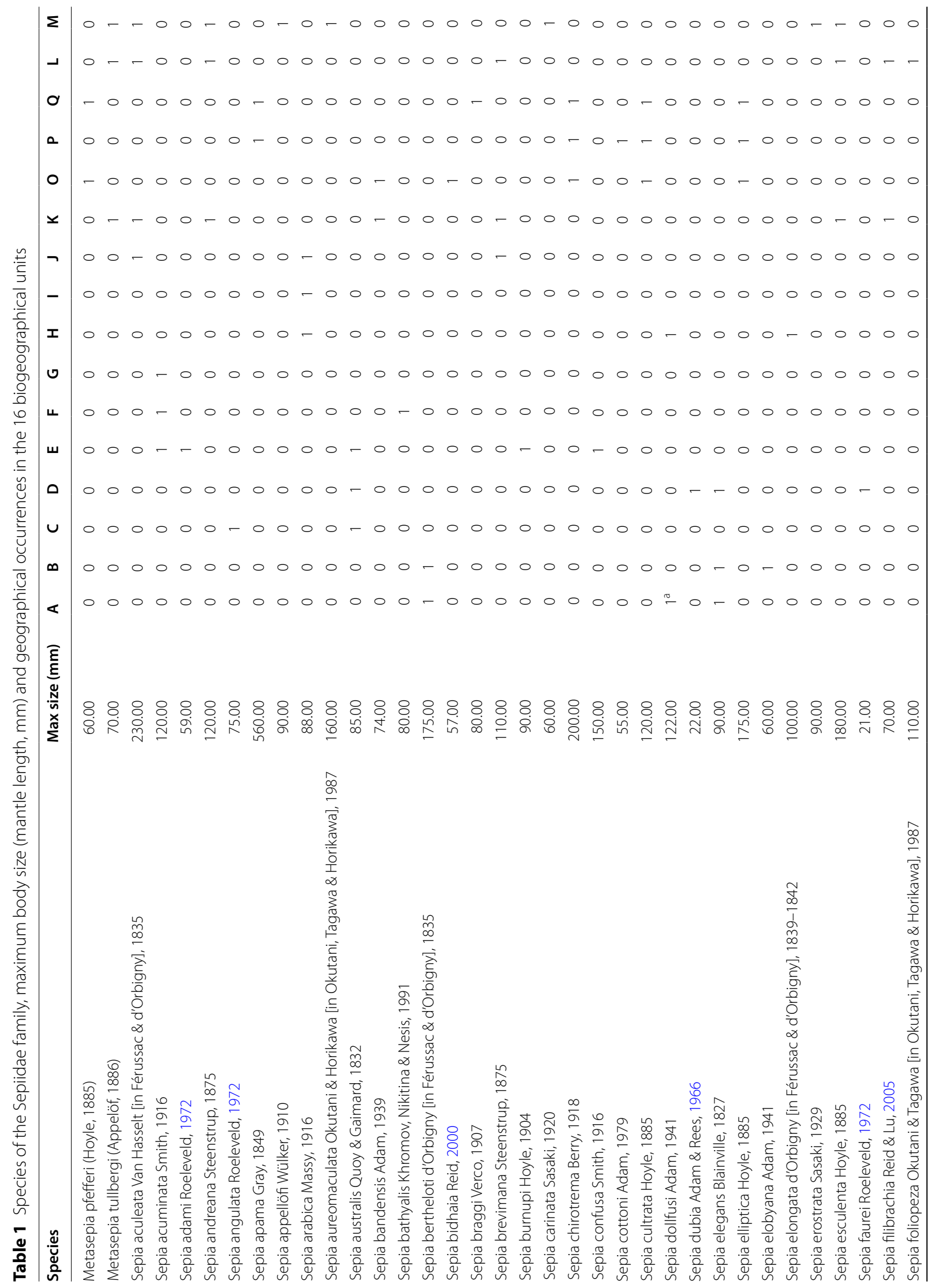




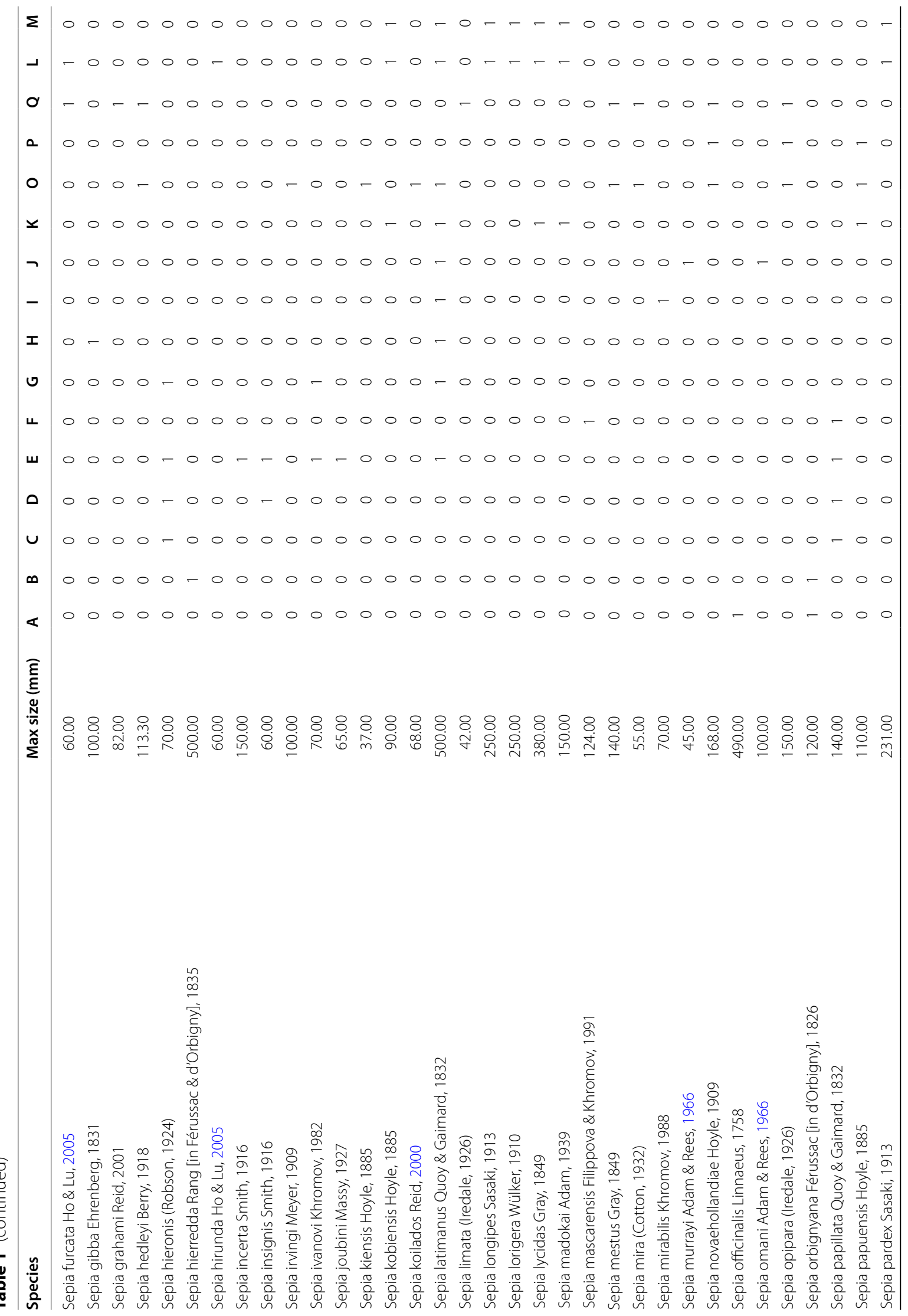




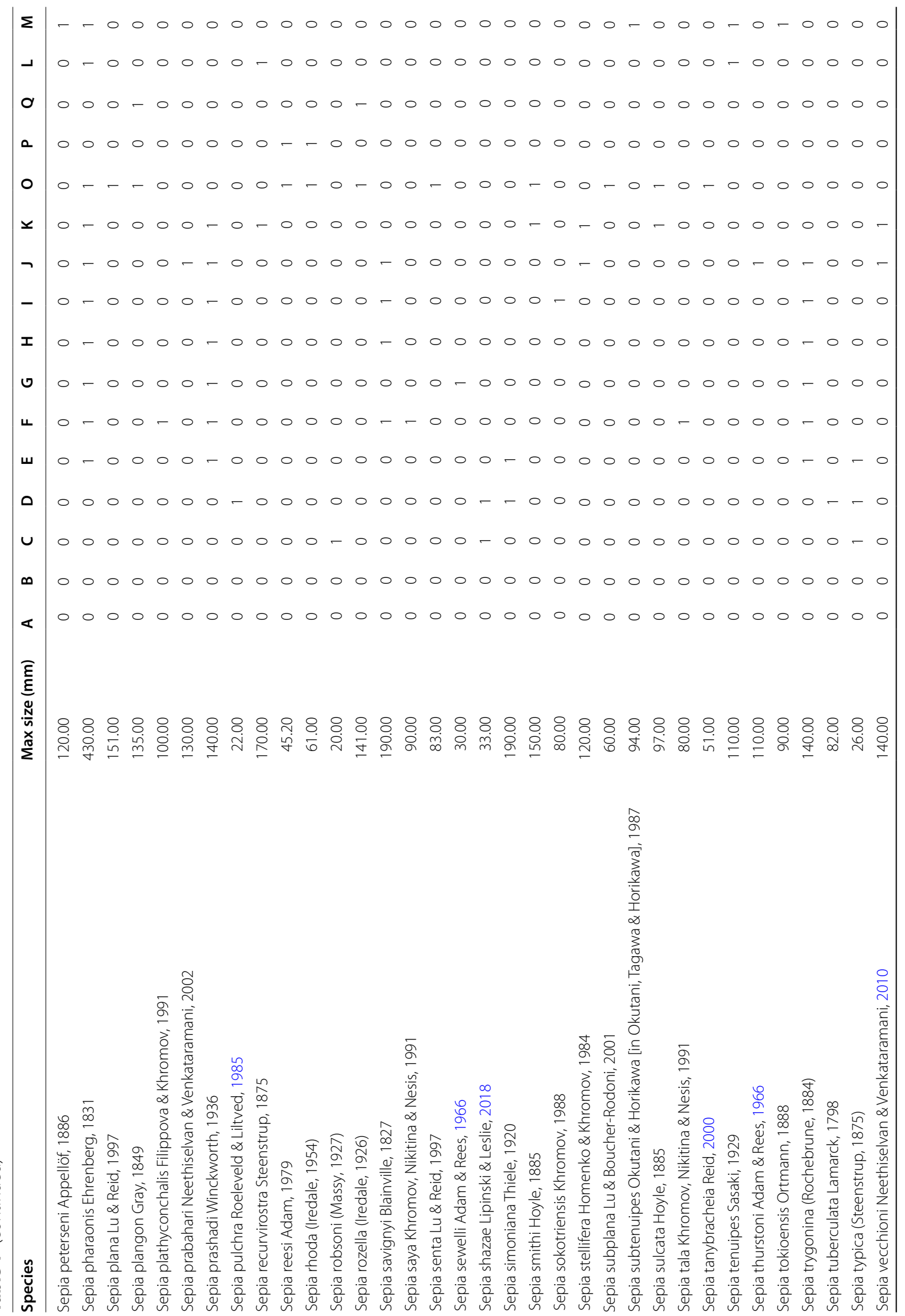




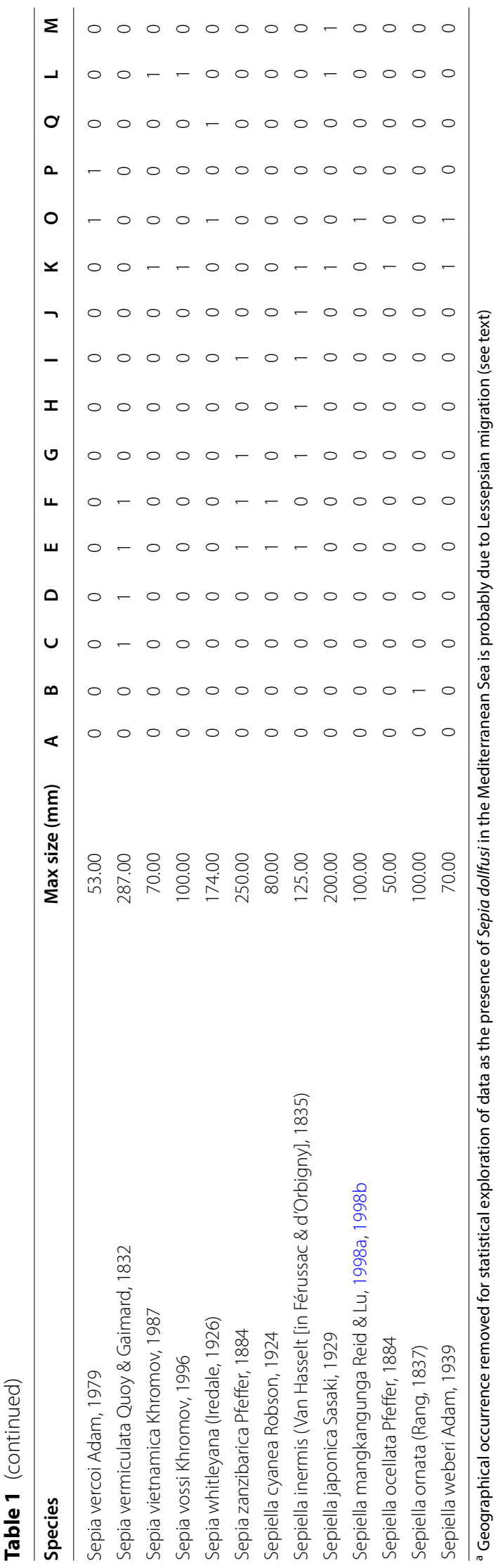


including 107, 7, and 2 species, respectively, Table 1) defined by morphological characters. Six "species complexes" have been proposed within the genus Sepia (Khromov et al., 1998) that still need to be phylogenetically explored (Allcock et al., 2015): 'Acanthosepion', 'Anomalosepia', 'Doratosepion', 'Hemisepius', 'Rhombosepion', and 'Sepia'. These species-complexes have been episodically used as sub-genera (or even sometimes as genera) by some authors. However, their monophyly is by no means confirmed (see Yoshida et al., 2010).

Here we use the dorsal mantle length (ML) as a measure of body size (Fig. 1). This is a standard descriptive character widely used in the literature (Roper \& Voss, 1983). The selected species body size for the present analysis corresponds to the maximum mantle length of species individuals quoted in the literature. We consider this measurement to represent the largest mature size of individuals for a species. In some rare cases, the maximum body length of a species comes from cuttlebone size measurement. This has been done when a cuttlebone length of a specimen of a given species exceeds any quoted ML. We only retain cases, where specific attribution of the cuttlebone does not suffer any doubt (see Lu, 1998a for a discussion about cuttlebones used for taxonomy). Species body size data come mainly from Reid et al. (2005) but include possible changes from more recent literature. Data were compared to older literature (and more specifically to various monographs) and no significant mismatches have been detected.

Data are explored here using both untreated and logtransformed measurements. This latter transformation is frequently used when comparing interspecific biological variations and aims to normalize the distribution of a biological variable, namely, body size for the present study (Gaston \& Blackburn, 2000; Gingerich, 2000; Harvey, 1982; LaBarbera, 1989).

Sepiids are to be found in coastal marine waters from Norway in the northwestern part of their range to the southernmost part of the Kamchatka Peninsula (Russia) in the northeastern part, and include Australia and eastern Melanesia and Micronesia (Fig. 2). The distribution of species in geographic space is synthetized on the basis of their presence in biogeographic units, following Neige (2003). Biogeographical units are basically delimited using "boundary compression" (taking the boundaries, where many species ranges meet as biogeographical boundaries, see Khromov, 1998). Sixteen biogeographic units are recognized (A-Q, Fig. 2), allowing distributional analysis of species (see Table 1). Only small changes are made compared to Neige (2003). Unit "N" has been aggregated with unit "O", because the former contains scattered data only (see Reid et al., 2005).
Following the seminal work of Reid (2016b), Voss (1974) draws attention to the effect of post-mortem drift in cuttlefish sepions that may blur the exact geographic distribution of living populations and, therefore, species. By comparing distributional ranges in species from living animals and from beach-collected cuttlebones in Australia, Reid observes geographic discrepancies of several hundred kilometers due to cuttlebone drift. She advises particular caution in interpreting distributional data, particularly when using electronic databases. In the present case, because distributional data are compiled primarily using basic published literature (expert-prepared range maps), we hope to avoid such pitfalls.

The geographical occurrences of the different sepiid species in the different geographical units are quoted thanks to previously published literature, and specially using data from Neige (2003). Only slight changes were made for northern sepiid distributions (Atlantic Ocean for the western part and Pacific Ocean for the eastern part) and for new records from Guam and the Cocos Islands (both records incorporated here into unit K), but no other major changes are made here. Among the latest literature, a landmark reference is the monograph published by Reid et al. (2005), which details geographical occurrences of most living species. Post 2005 literature has also been investigated and changes have been introduced in the present database when needed (Lipinski \& Leslie, 2018; Lu \& Chung, 2017; Neethiselvan \& Venkataramani, 2010; Norman et al., 2016; Reid, 2016a; Riad, 2015, 2020a,b). Sepia dollfusi has recently been found in Mediterranean waters, caught while commercial fish trawling in the area off Alexandria (Riad, 2015). This species was previously known from the Red Sea only and its recent presence along Egypt's Mediterranean coast may be interpreted as an instance of Lessepsian migration (Bello et al., 2020). For that reason, this presence is removed from our database when processing geographic data analysis.

\section{Statistics}

Statistics have been computed using Past 4.04 freeware (Hammer et al., 2001) including graphs, tests (mostly non-parametric), and cluster dendrograms (similarity analysis). The latter were established by the unweighted pair group method with the arithmetic mean algorithm (UPGMA). Dendrogram robustness was assessed by bootstrap values (after 500 runs) and by the cophenetic correlation coefficient that measures the distortion between each dendrogram and the corresponding matrix of similarity. 


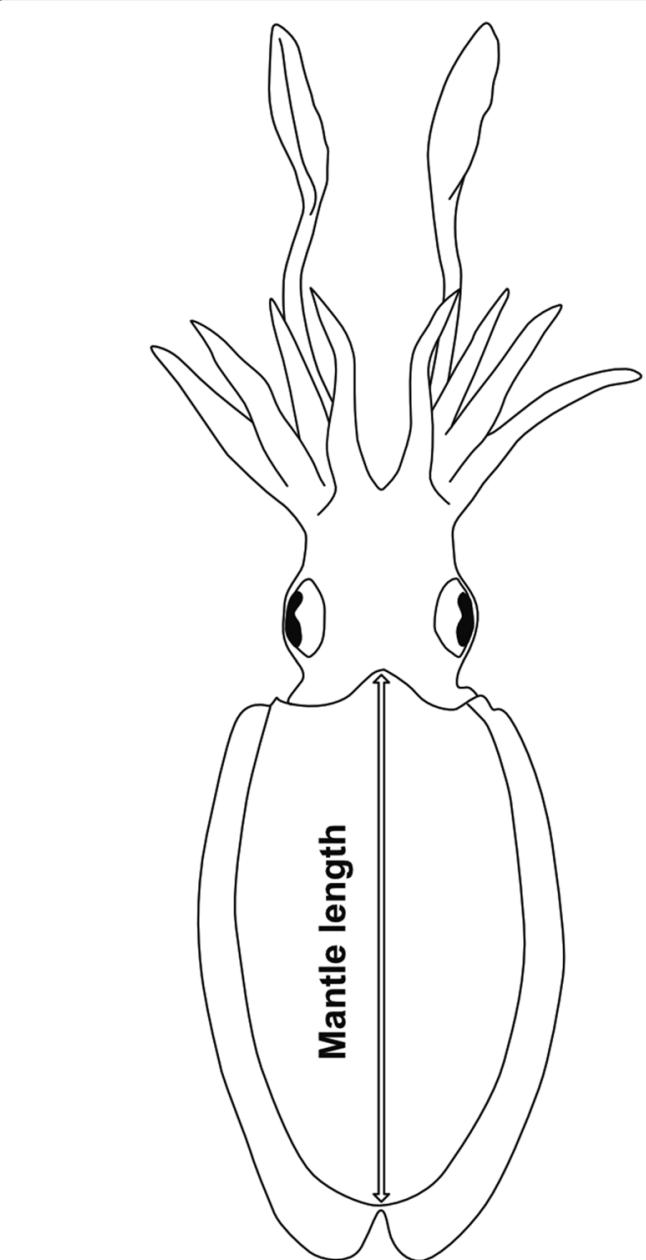

Fig. 1 Dorsal view of a cuttlefish showing standard dorsal mantle length measurement (ML)

\section{Results}

\section{Body size patterns}

Body size of cuttlefishes (ML) varies from nearly $20 \mathrm{~mm}$ (Sepia robsoni, S. faurei, S. dubia, S. pulchra) to $560 \mathrm{~mm}$ (Sepia apama, the "giant cuttlefish"). The mean size for a cuttlefish is $125.16 \mathrm{~mm}$ (ML). Raw data exhibit strong right skewness (2.52, Table 2) and high kurtosis (7.21, Table 2) indicating, respectively, a non-normal and peaked distribution. Sepia and Sepiella genera display a large variation in size (Fig. 3; Table 2). Mean body sizes of Sepia and Sepiella species are not far apart $(127.70 \mathrm{~mm}$ and $103.57 \mathrm{~mm}$, respectively), whereas Metasepia are smaller ( $65 \mathrm{~mm}$; Table 2).

Log data are close to a normal distribution (skewness is 0.12 , whereas kurtosis is 0.72 , Table 2). However, the distribution of body size within the sepiid family (Fig. 4A) does not display normality for log-transform mantle length (Shapiro-Wilk normality $=0.98, p=0.04$ ). As highlighted by the normal probability plot (Fig. 4B), this is probably due to an over-representation of small and large body sizes that may be considered as outliers in the context of a normal distribution of data (see left and right tails of the histogram, Fig. 4A).

\section{Geography of body size}

Biogeographical units share quite similar body size variation features (Fig. 5; Table 3) except for units C and D. Body size means in these two units are particularly small. However, large differences between the number of species in the different biogeographical units (from 4 to 31 species, Table 3) dramatically limit comparisons between these units and preclude any robust statistical comparisons between them.

To describe body size variations for large geographical areas and to test for potential statistical differences, an attempt is made to gather biogeographical units with hierarchical clustering, using species presence/absence (Table 1). Basically this similarity analysis method is used to identify biogeographical clusters with comparable sets of species (see Freitas et al., 2019 for an up-to-date use of the technique). In turn, identification of these biogeographical clusters emphasizes large-scale body size patterns. Different similarity indexes were tested using different aggregation methods and yielded comparable results. The one shown here uses the UPGMA aggregation method and the Raup-Crick similarity index. The dendrogram obtained provides robust nodes: most show high bootstrap values (Fig. 6). The deepest node separates the Australian coasts (biogeographical units O, P, and Q) from others, which are split in two blocks: the Atlantic Ocean (biogeographical units A-D) and the Indian and Pacific Oceans. Each of these two clusters also splits into two. The Atlantic Ocean units are organized into an "Atlantic" biogeographic cluster $(\mathrm{A}+\mathrm{B})$ and a "Cape Basin" cluster $(C+D)$, and the rest splits into an "Indian Ocean" cluster (E-J) and an "Asia-Pacific" cluster (K-M). Together with the "Australia" one, these five clusters reflect the primary biogeographic distribution of sepiids. Interestingly, this clustering does not simply follow the coastlines from the northwest (A) to the northeast (M) or southeast $(\mathrm{Q})$ biogeographical units.

These five biogeographical clusters (see Fig. 6 bottom) are well supported (high bootstrap values, Fig. 6) and are used to compare interspecific body size variation within sepiids at a large scale. The most striking pattern is the small mean body size of cuttlefishes for the Cape Basin cluster (Fig. 5, "biogeographical clusters") due to the over-representation of small species and the absence of large species, compared to other clusters. This pattern is confirmed using a non-parametric Kruskal-Wallis test, which proposes as its null hypothesis that all samples (biogeographical clusters here) come from the same 


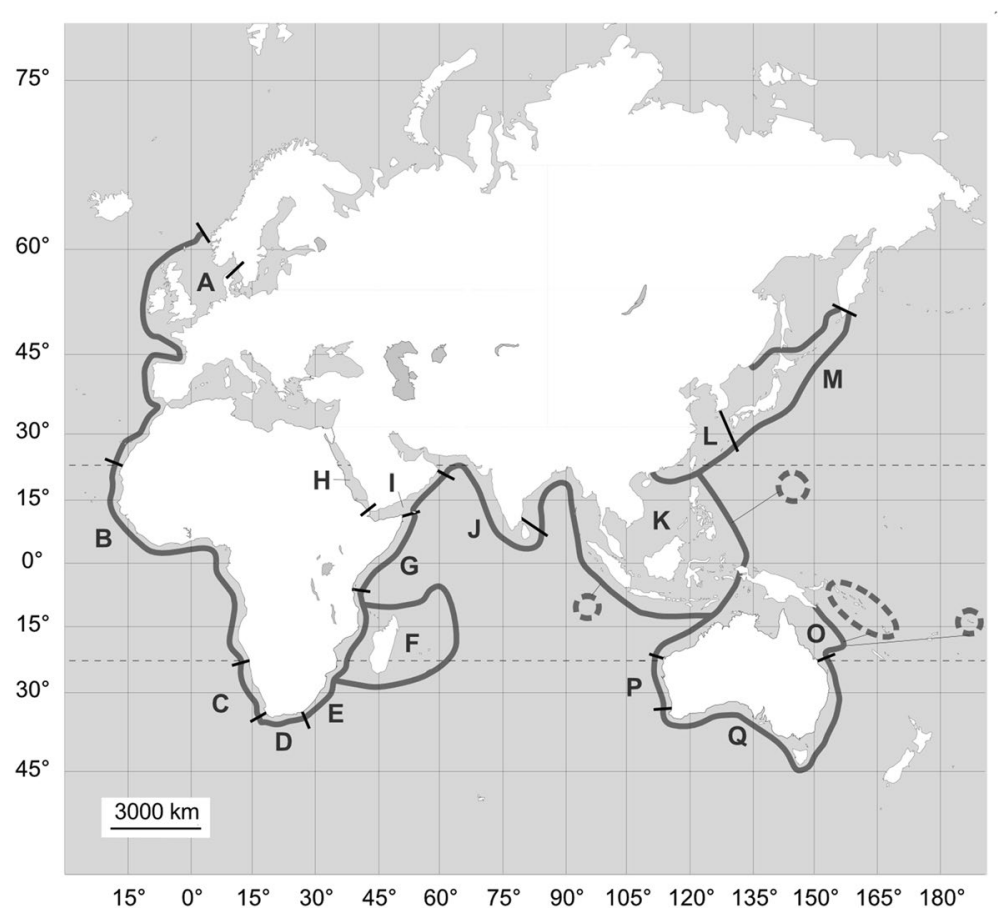

Fig. 2 Geographical distribution of sepiids and biogeographical units selected for this study

Table 2 Descriptive statistics of body size (ML $\mathrm{mm}$ and Log ML) for extant Sepiidae for all species together and for each genus of the family

\begin{tabular}{llllll}
\hline & & All & Metasepia & Sepia & Sepiella \\
\hline Data & $n$ & 116 & 2 & 107 & 7 \\
Raw data (ML) & Min & 20.00 & 60.00 & 20.00 & 50.00 \\
& Max & 560.00 & 70.00 & 560.00 & 200.00 \\
& Mean & 125.16 & 65.00 & 127.70 & 103.57 \\
& Median & 100.00 & 65.00 & 100.00 & 100.00 \\
& SD & 99.24 & 7.07 & 102.19 & 48.88 \\
& Skewness & 2.52 & 0.00 & 2.44 & 1.40 \\
& Kurtosis & 7.21 & -2.75 & 6.62 & 2.49 \\
Log transformed & Min & 1.3 & 1.78 & 1.30 & 1.70 \\
data (Log ML) & Max & 2.75 & 1.85 & 2.75 & 2.30 \\
& Mean & 2.00 & 1.81 & 2.01 & 1.98 \\
& Median & 2.00 & 1.81 & 2.00 & 2.00 \\
& SD & 0.28 & 0.05 & 0.29 & 0.19 \\
& Skewness & 0.12 & 0.00 & 0.08 & 0.36 \\
& Kurtosis & 0.72 & -2.75 & 0.63 & 0.64 \\
\hline
\end{tabular}

population. The test is rejected $(H=12.34, p=0.01)$ indicating that at least one pair of biogeographical clusters has different body size medians. Dunn's post hoc test indicates that the Cape Basin cluster is systematically different from the others ( $p$ values consistently lower than
0.01 ) and that no other difference between pairs of clusters occurs.

\section{Bergmann's rule}

We calculated the mean latitude for each biogeographical unit and compared it to the mean body size of the species from the unit (Fig. 7). To test for Bergmann's rule, all mean latitude values have been transformed into their absolute values. No body size-latitude trend occurs (Spearman's $r=0.07, p=0.79$ ). The same exploration was conducted but omitting units $C$ and $D$ which display a particular pattern with significantly smaller mean body sizes (see above). As with the complete data set, no body size-latitude trend occurs (Spearman's $r=0.31, p=$ 0.28).

\section{Discussion}

\section{Body size patterns}

Our study reveals a large body size variation among sepiids at a ratio of about 1:30 (considering mantle length). The distribution is strongly right-skewed for untransformed data. When body sizes are logarithmically transformed, their distribution (Log of ML) approximates a typical normal shape but without statistically fitting it. This is due to an overrepresentation of extremely small and large species. However, compared to other published data (see Gaston \& Blackburn, 2000), sepiid body 


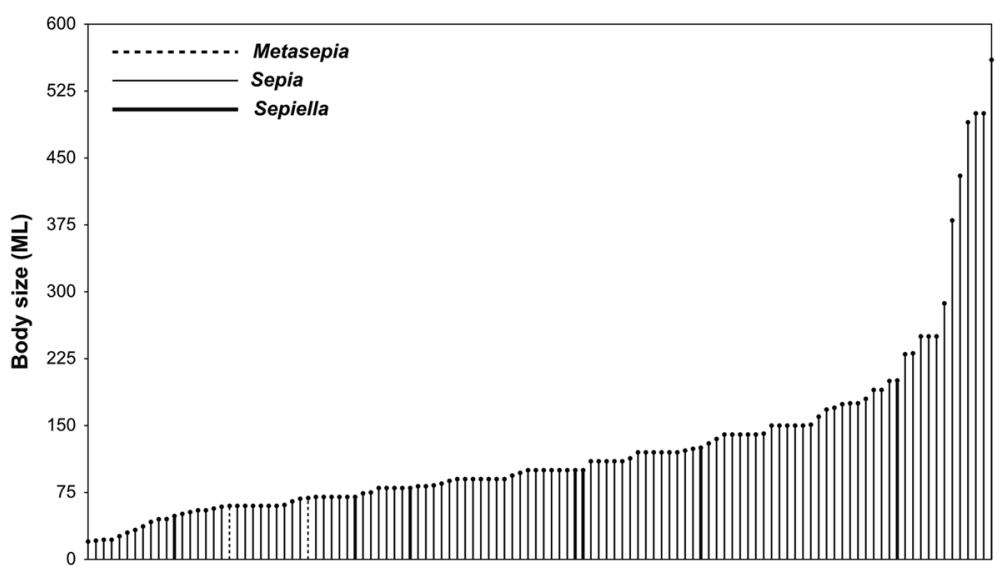

Fig. 3 Body size data (ML) for the 116 sepiid species from smallest to largest. Each vertical bar represents a species

size distribution (once logarithmically transformed) remains relatively close to a normal distribution pattern. Indeed, distribution of body size at the interspecific scale is frequently right log-skewed, with some exceptions, such as for aquatic birds (Gaston \& Blackburn, 1995) or marine bivalves (Roy et al., 2000). The reasons for this
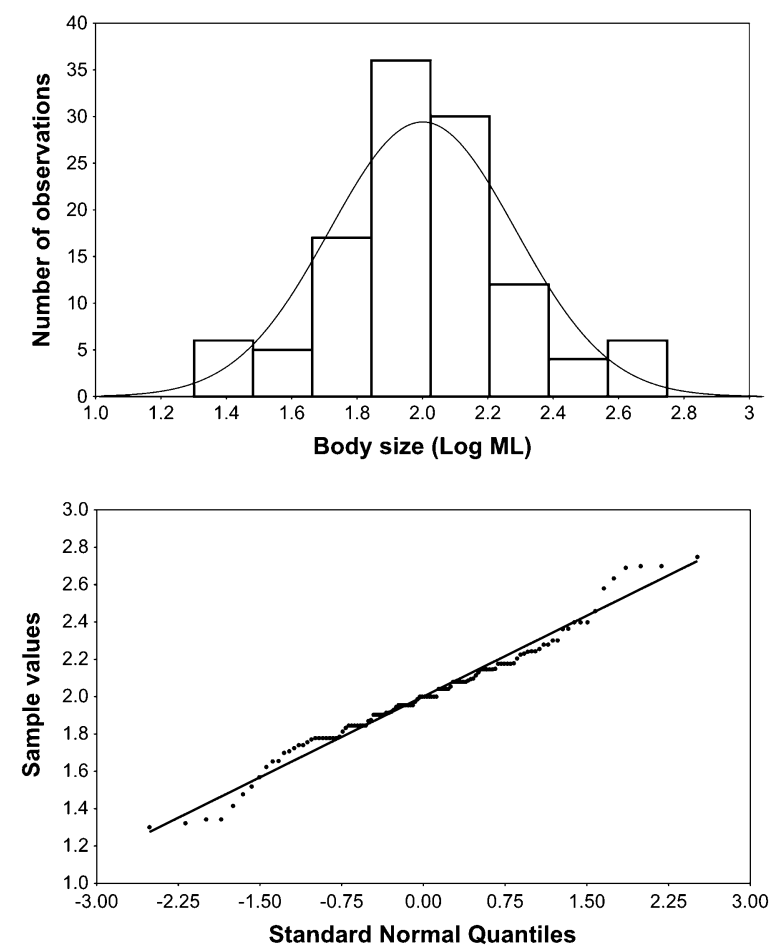

Fig. 4 Top: the frequency distribution of Log transformed body sizes of the cuttlefish species of the world $(n=116)$. Bottom: normal probability plot of the same data used to evaluate the skewness of the body size distribution prevalence of right-skewed distributions remains largely unclear. Undiscovered species, taxonomical or geographical scales of investigation, preferential speciation for small species versus extinction for big ones, and energetic optima are all plausible explanations (Kozłowski \& Gawelczyk, 2002).

For sepiids, an interesting hypothesis to be tested could be a phylogenetic effect, which could cause the overrepresentation of the smallest and largest species (i.e., the presence of particular clades with species of small or large body sizes). Species of the smallest size have been gathered into the 'Hemisepius' species-complex, or alternatively the Sepia (Hemisepius) subgenus (see for different alternatives Adam \& Rees 1966; Khromov, 1998; Roeleved, 1972; Roeleveld \& Liltved, 1985;). Whatever its taxonomical rank, in total, five species are generally considered to belong to this clade: S. dubia, S. faurei, S. pulchra, S. robsoni, and S. typica. They are the five smallest species in our database, ranging from 20 to $26 \mathrm{~mm}$ (mantle length) and their geographical distributions are strictly restricted to Cape Basin waters. They share a set of common characters and display differences that may reveal two closed groups: one with an hemisepiid shell (an abbreviated phragmocone) and the other with a normal shell (Roeleveld \& Liltved, 1985). Hence a phylogenetic effect could be suspected: a set of five small species, which explain the overrepresentation of small body size within the sepiids. Recently, a sixth small species (S. shazae) has been discovered again in Cape Basin waters (Lipinski \& Leslie, 2018). However, strengthening the phylogenetic effect, its discovery challenges the status of the 'Hemisepius' group. In their conclusion, Roeleveld and Liltved (1985) note that the only shared character between S. shazae and S. dubia is their small size, and clustering the six small species would unite highly 


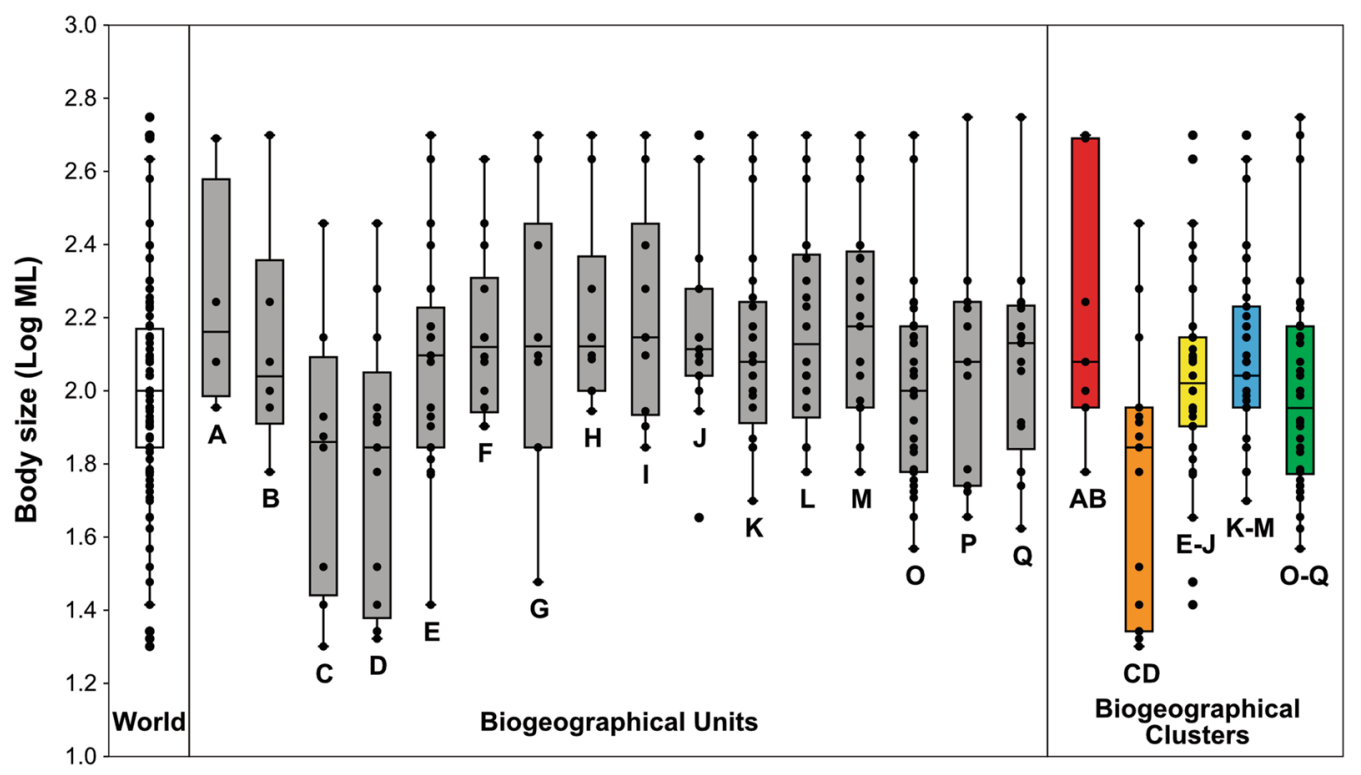

Fig. 5 Box and whisker plots for cuttlefish body size (Log ML): body size of species (points), mean, and standard error. Points not connected with the vertical bar are outliers. Left: for all living species of the world; middle: for each biogeographical unit; right: for the five biogeographical clusters (see text)

Table 3 Descriptive statistics of mean body size (Log ML) for the 16 biogeographical units

\begin{tabular}{|c|c|c|c|c|c|c|c|c|c|c|c|c|c|c|c|c|c|}
\hline & & A & B & C & D & E & $F$ & G & $\mathrm{H}$ & I & J & K & L & $M$ & 0 & $P$ & $\mathbf{Q}$ \\
\hline Data & $n$ & 4 & 6 & 8 & 13 & 21 & 14 & 10 & 10 & 10 & 15 & 25 & 22 & 21 & 31 & 11 & 17 \\
\hline \multirow{7}{*}{$\begin{array}{l}\text { Log trans- } \\
\text { formed data } \\
(\log M L)\end{array}$} & Min & 1.95 & 1.78 & 1.30 & 1.32 & 1.41 & 1.90 & 1.48 & 1.94 & 1.85 & 1.65 & 1.70 & 1.78 & 1.78 & 1.57 & 1.66 & 1.62 \\
\hline & Max & 2.69 & 2.70 & 2.46 & 2.46 & 2.70 & 2.63 & 2.70 & 2.70 & 2.70 & 2.70 & 2.70 & 2.70 & 2.70 & 2.70 & 2.75 & 2.75 \\
\hline & Mean & 2.24 & 2.13 & 1.81 & 1.79 & 2.08 & 2.15 & 2.14 & 2.20 & 2.21 & 2.16 & 2.12 & 2.17 & 2.19 & 2.01 & 2.07 & 2.07 \\
\hline & Median & 2.16 & 2.04 & 1.86 & 1.85 & 2.10 & 2.12 & 2.12 & 2.12 & 2.15 & 2.11 & 2.08 & 2.13 & 2.18 & 2.00 & 2.08 & 2.13 \\
\hline & SD & 0.32 & 0.32 & 0.39 & 0.38 & 0.31 & 0.23 & 0.37 & 0.26 & 0.29 & 0.26 & 0.25 & 0.28 & 0.26 & 0.27 & 0.33 & 0.27 \\
\hline & Skewness & 1.25 & 1.30 & 0.30 & 0.23 & 0.18 & 0.87 & -0.05 & 1.27 & 0.57 & 0.60 & 0.77 & 0.32 & 0.40 & 0.68 & 0.63 & 0.55 \\
\hline & Kurtosis & 1.46 & 2.07 & -0.54 & -1.02 & 0.28 & 0.10 & -0.10 & 0.43 & -0.75 & 1.26 & 0.32 & -0.86 & -0.75 & 0.57 & 0.42 & 1.29 \\
\hline
\end{tabular}

contrasting characters under one name thereby reinforcing the argument that 'Hemisepius' does not represent a monophyletic group. Consequently, it is speculative to affirm that so many small species occur within sepiids because of the effect of a particular clade characterized by species of small body size. One way forward would be to develop phylogenetic hypotheses including a large number of species and completing those already published (Allcock et al., 2015; Bonnaud et al., 2006; Yoshida et al., 2006, 2010).

At the other end of the range of body size variations, six very large species with mantle lengths exceeding $350 \mathrm{~mm}$ are found (S. apama, S. hierredda, S. latimanus, S. officinalis, S. pharaonis, and S. lycidas from largest to smallest, respectively). Five of these (S. apama, S. hierredda,
S. latimanus, S. officinalis, and S. pharaonis) have been clustered into a 'Sepia' group (Khromov et al., 1998). However, members of this speciose group are not characterized by their large size (most are medium-sized). And even if it was the case, it is worth noting that this group is far from being considered as a clade. Once again, the phylogenetic effect cannot be demonstrated.

\section{Geography of body size}

At a large scale and based on presence/absence clustering of species, the present study subdivides the living area of sepiids into five main clusters (Fig. 6): Atlantic, Cape Basin, Indian Ocean, Asia-Pacific, and Australia. They do not exactly fit the Marine Ecoregions of the World (MEOW) published by Spalding et al. 

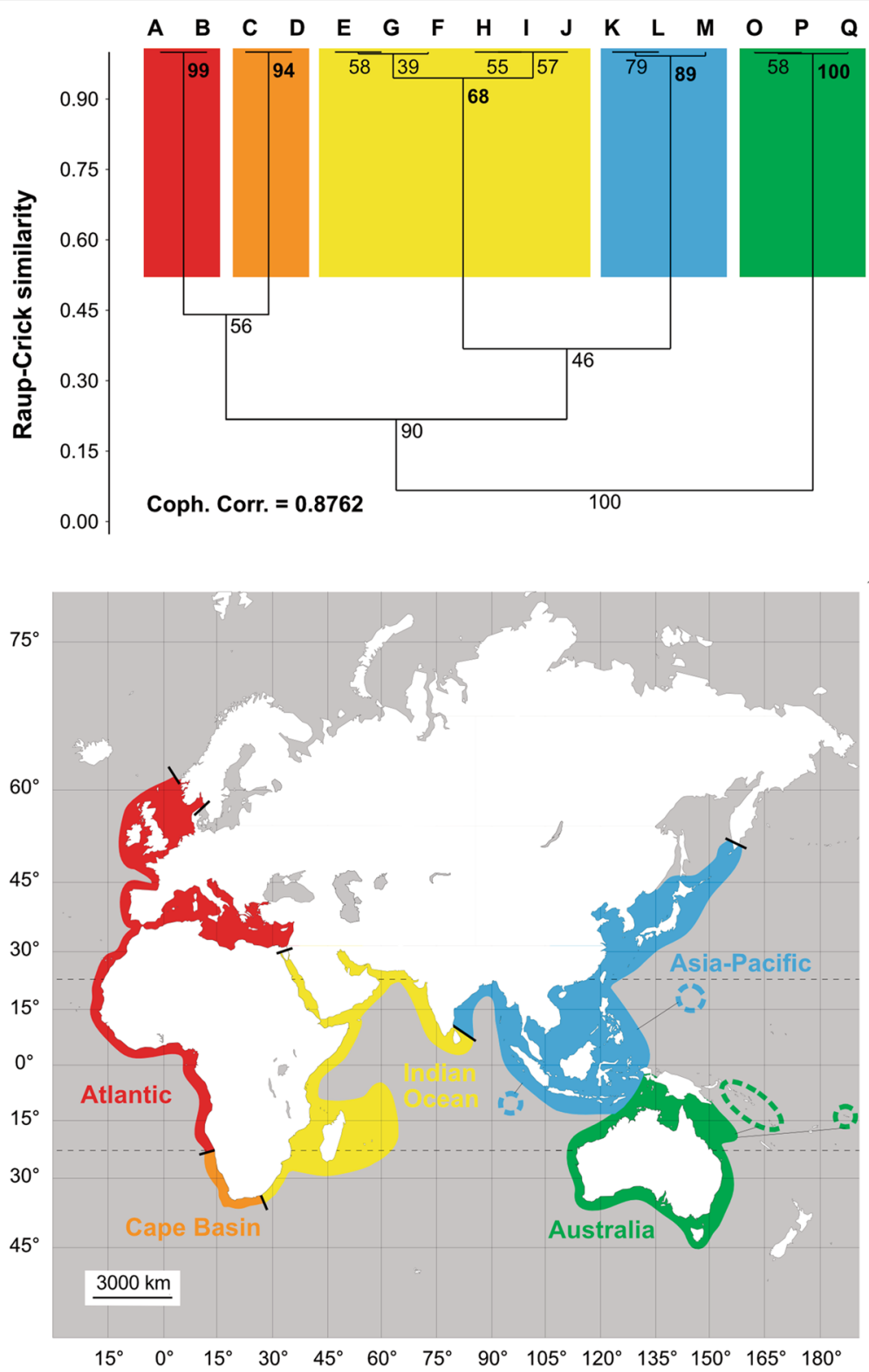

Fig. 6 Top: similarity analysis of cuttlefish assemblages represented by cluster dendrograms with bootstrap values for each node (see text). Colors reveal the main biogeographical clusters: Atlantic, Cape Basin, Indian Ocean, Asia-Pacific, Australia. Bottom: world divided into the five biogeographic clusters according to the similarity analysis

(2007) and based on a large study of coastal and shelf area biotas already published. However, the method employed here is based on biogeographical units and induces some biases (see below). Nixon (2010), mainly following Khromov's data (1998), also proposed to divide the world, where sepiids live in five areas. She assumed a "world divided artificially" (Nixon, 2010, Figure 5.1). Her qualitative approach led to comparable results to ours, even if the comparison is complicated by the absence of clear boundaries for some of Nixon's clusters. Anyway, one interesting difference occurs for southern African coasts. Nixon identified a cluster running right around the southern tip of Africa (on both sides from a little south of the Tropic of Capricorn). The present study divides southern African coasts. The southern and western parts (units $\mathrm{D}$ and $\mathrm{C}$, respectively, see Fig. 2) form a cluster of their own, while the eastern part (unit E, see Fig. 2) fits with east African coasts and forms part of the Indian Ocean cluster. This pattern partially corresponds to the "Temperate 


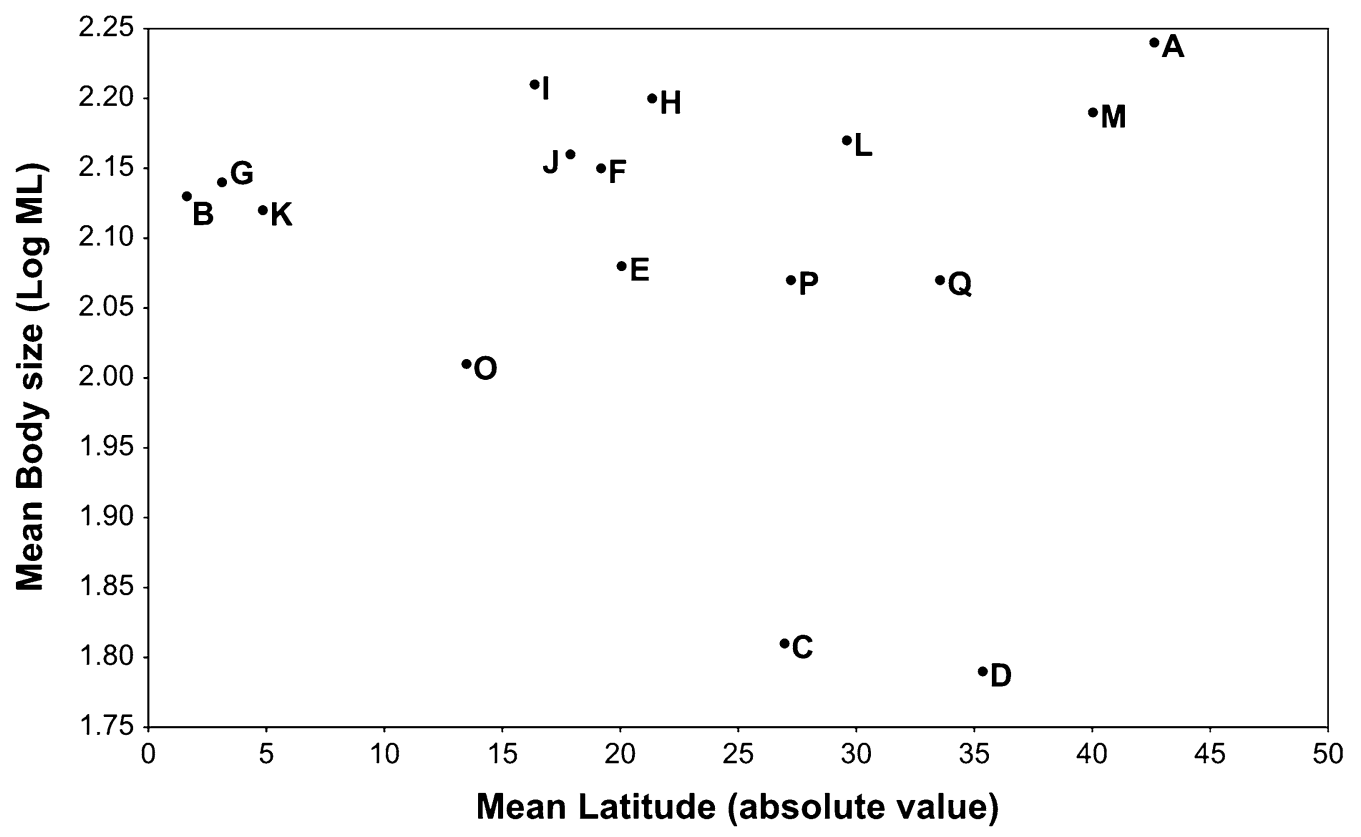

Fig. 7 Relationship between the mean latitude of biogeographical units and mean body size (Log ML) of present species in each unit

Southern African" realm (Benguela plus part of Agulhas provinces) as defined by Spalding et al. (2007).

On a smaller scale, two striking patterns have been observed and are probably interconnected. One is the significantly different mean body size of cuttlefish species for southwestern Africa (Fig. 5). The other is the separation of the Atlantic faunal cluster from the east African one (Fig. 6), the latter being much more closely related to the Indian Ocean cluster than to the former. The singularity of southwest Africa was already noticed by Khromov (1998) who reported its high endemic rate. He also pointed out the relatively low species richness of European and west African coasts (from A to $\mathrm{C}$ according to biogeographical units recognized there) relative to western Indian ones (Khromov, 1998; Fig. 1). For him, living conditions are of prime importance for explaining species richness differences (winter sea temperatures, hydrological barriers, cold currents, such as the Benguela current) even if he did not exclude some artefacts (poor knowledge of some island areas). Neige (2003) calculated a high morphological disparity of cuttlebone/species richness ratio for southwest African (units $C$ and $D$ ), and proposed that such a singular area (southwest Africa) may result from the coexistence of two independent phylogenetic clusters of species, one from the Atlantic Ocean and the other from the Indian Ocean. This is compatible with the suggestion of Khromov (1998) of a colonization in several phases for sepiids, one of them being their expansion into the Atlantic Ocean during the Miocene and Early Pliocene. As already noticed an alternative hypothesis would be the presence of two sets of species and of a phylogenetic cluster ('Hemisepius'). This hypothesis would also explain the split between the Atlantic and the Indian Ocean faunal clusters. Once again, a robust phylogenetic hypothesis for sepiids is needed.

Finally, the attempt to demonstrate that Bergmann's rule applies to the distribution of sepiid body size was unsuccessful. However, the association of small latitudinal range biogeographic units $(\mathrm{C}, \mathrm{D}, \mathrm{I}, \mathrm{P})$ with large latitudinal range ones $(\mathrm{B}, \mathrm{K}, \mathrm{M})$ as used here may have blurred the results.

\section{Caveats}

The present attempt to illustrate the geography of body size in cuttlefishes at the interspecific scale yields results and calls for certain caveats.

The first caveat is linked with the quantification of body size. Dorsal mantle length does not involve any problems (this is clearly a standard measurement, Reid, 2016a; Roper \& Voss, 1983) but the data used here consider a single value of maximum mantle length for a species, wherever the species lives. For species with large geographical ranges this may be an oversimplification. For example, Reid et al. (2005) noted a large difference in body size between specimens of $S$. officinalis living in temperate waters (body size up to $490 \mathrm{~mm}$, the body size used here for analyses, see Table 1) and specimens living in subtropical areas (body size up to $300 \mathrm{~mm}$ ). This 
phenomenon clearly alters the present results, and particularly the attempt to recognize Bergmann's rule. Differentiated measurements according to geographical areas would be an interesting way to resolve this problem, but we have to acknowledge that such data are available for a handful of sepiid species only.

The definition and use of biogeographical units calls for a second caveat. The present analysis is based on the recognition of points of occurrence of species in a set of pre-established biogeographical units (determined using 'boundary compressions'). The transformation of biogeographical units into smaller ones or into pure geographical slicing (see Berke et al., 2013 for an example involving marine bivalves) or the use of expert-prepared range maps (such as those of Reid et al., 2005) could provide interesting alternatives for exploring biogeographic patterns (including the geography of body size), although it should be remembered that each has its own shortcomings (Rotenberry \& Balasubramaniam, 2020). Pure geographical slicing would clearly favor the comparison between geographical distribution of cuttlefishes and environmental variables.

\section{Conclusion}

Using data from the literature, I have compiled a database of maximum body size (dorsal mantle length) for cuttlefishes. Coupled with a geographical overview of sepiid distribution into 16 biogeographical units, the geography of body size at the interspecific scale is thus explored. Results reveal a strongly skewed distribution of body size variation for crude values and a nearly normal distribution when data are log-transformed. However, normality is not statistically validated because of the overrepresentation of small and large species.

Globally, the presence/absence of species in biogeographical units fall into five main clusters: Atlantic, Cape Basin, Indian Ocean, Asia-Pacific (including northeastern distribution), and Australia. My results (based on quantitative clustering) globally fit those obtained from qualitative approaches (i.e., expert-based approaches: Khromov, 1998; Nixon, 2010). An interesting difference occurs for southern African coasts. Here, we show that southern and western parts (Cape Basin cluster) are related to west African coasts (Atlantic cluster), while the eastern part goes with east African coasts (Indian Ocean cluster). Reasons probably involve the mixing of phylogenetic and environmental effects.

On average, clusters display more or less the same mean body size pattern except for the Cape Basin cluster, which is statistically different from the others (interspecific mean body size is smaller). The reasons remain unclear but a phylogenetic effect is suspected as species from the 'Hemisepius' complex (which comprises small species) concentrate in Cape Basin coastal waters. Further studies covering the broad phylogeny of cuttlefishes and based on alternative biogeographical approaches are needed to explore in detail the geography of body size in cuttlefishes or any other ecogeographic pattern.

\section{Abbreviation \\ ML: Dorsal mantle length.}

\section{Acknowledgements}

This paper is dedicated to Sigurd von Boletzky who was my host at Banyulssur-Mer, while I was finishing my PhD (1995). He explained the fundamentals of "living cephalopods" to me. For me, Sigurd will always be the man who knew about cephalopods ... and cephalopod scholars.

\section{Authors' contributions}

All made by myself (single author). The author read and approved the final manuscript.

Funding

No funding.

Availability of data and materials

Table 1 included in the manuscript.

\section{Declarations}

Competing interests

The authors declare that they have no competing interests.

Received: 15 April 2021 Accepted: 2 July 2021

Published online: 28 July 2021

\section{References}

Adam, W., Adam, W., \& Rees, W. J. (1966). A review of the cephalopod family Sepiidae. Scientific Reports/John Murray Expedition, 1933-34(11), 1-165.

Allcock, A. L., Lindgren, A., \& Strugnell, J. M. (2015). The contribution of molecular data to our understanding of cephalopod evolution and systematics: A review. Journal of Natural History, 49(21-24), 1373-1421.

Bello, G., Andaloro, F., \& Battaglia, P. (2020). Non-indigenous cephalopods in the Mediterranean Sea: A review. Acta Adriatica, 61(2), 113-134.

Berke, S. K., Jablonski, D., Krug, A. Z., Roy, K., \& Tomasovych, A. (2013). Beyond Bergmann's rule: Size-latitude relationships in marine Bivalvia world-wide. Global Ecology and Biogeography, 22(2), 173-183.

Blackburn, T. M., \& Gaston, K. J. (1994). Animal body size distributions: Patterns, mechanisms and implications. Trends in Ecology and Evolution, 9(12), 471-474.

Blackburn, T. M., Gaston, K. J., \& Loder, N. (1999). Geographic gradients in body size: A clarification of Bergmann's rule. Diversity and Distributions, 5(4), 165-174.

Boletzky, S. V. (1998). Cephalopod eggs and egg masses. Oceonography and Marine Biology: An Annual Review, 36, 341-371.

Bonnaud, L., Lu, C. C., \& Boucher-Rodoni, R. (2006). Morphological character evolution and molecular trees in sepiids (Mollusca: Cephalopoda): Is the cuttlebone a robust phylogenetic marker? Biological Journal of the Linnean Society, 89(1), 139-150.

Carlini, D. B. (2010). Molecular systematics of the Coleoidea. Treatise Online, 15, $1-8$.

Chown, S. L., \& Gaston, K. J. (2010). Body size variation in insects: A macroecological perspective. Biological Reviews, 85(1), 139-169.

Denton, E. J., \& Gilpin-Brown, J. B. (1961a). The buoyancy of the cuttlefish. Journal of the Marine Biological Association of the United Kingdom, 41(02), 319-342. 
Denton, E. J., \& Gilpin-Brown, J. B. (1961b). The distribution of gas and liquid within the cuttlebone. Journal of the Marine Biological Association of the United Kingdom, 41(2), 365-381.

Dommergues, J. L., Montuire, S., \& Neige, P. (2002). Size patterns through time: The case of the early jurassic ammonite radiation. Paleobiology, 28(4), 423-434.

Freitas, R., Romeiras, M., Silva, L., Cordeiro, R., Madeira, P., González, J. A., et al. (2019). Restructuring of the'Macaronesia' biogeographic unit: A marine multi-taxon biogeographical approach. Scientific Reports, 9(1), 1-18.

Gaston, K. J., \& Blackburn, T. M. (1995). The frequency distribution of bird body weights: Aquatic and terrestrial species. Ibis, 137(2), 237-240.

Gaston, K. J., \& Blackburn, T. M. (2000). Pattern and process in macroecology. Blackwell.

Gaston, K. J., Chown, S. L., \& Evans, K. L. (2008). Ecogeographical rules: Elements of a synthesis. Journal of Biogeography, 35(3), 483-500.

Gingerich, P. D. (2000). Arithmetic or geometric normality of biological variation: An empirical test of theory. Journal of Theoretical Biology, 204(2), 201-221.

Guerra, A., Robin, J. P., Sykes, A., Koutsoubas, D., Jereb, P., Lefkaditou, E., Koueta, N., \& Allcock, A. L. (2015). Sepia officinalis Linnaeus, 1758. In P. Jereb, A L. Allcock, E. Lefkaditou, U. Piatkowsk, L. C. Hastie, \& G. J. Pierce (Eds.), Cephalopod biology and fisheries in Europe: II. Species Accounts (pp. 53-72). International Council for the Exploration of the Sea.

Hammer, Ø., Harper, D. A. T., \& Ryan, P. D. (2001). PAST: Paleontological statistics software package for education and data analysis. Palaeontologia Electronica, 4(1), 1-9.

Harvey, P. H. (1982). On rethinking allometry. Journal of Theoretical Biology, 95, 37-41.

Ho, C.-W., \& Lu, C.-C. (2005). Two new species of Sepia (Doratosepion) (Cephalopoda: Sepiidae) from Taiwan, based on morphological and molecular data. Phuket Marine Biological Centre Research Bulletin, 69, 51-69.

Jablonski, D. (1997). Body-size evolution in cretaceous molluscs and the status of Cope's rule. Nature, 385(6613), 250-252.

Khromov, D. N. (1998). Distribution patterns of Sepiidae. Smithsonian Contributions to Zoology, 586, 191-206.

Khromov, D. N., Lu, C. C., Guerra, A., Dong, Z., \& Boletzky, S. V. (1998). A synopsis of Sepiidae outside Australian waters (Cephalopoda: Sepioidea). Smithsonian Contribution to Zoology, 586, 77-157.

Kozłowski, J., \& Gawelczyk, A. T. (2002). Why are species' body size distributions usually skewed to the right? Functional Ecology, 16(4), 419-432.

LaBarbera, M. (1989). Analyzing body size as a factor in ecology and evolution. Annual Review of Ecology and Systematics, 20(1), 97-117.

Lipinski, M. R., \& Leslie, R. W. (2018). A new species of Sepia (Cephalopoda: Sepiidae) from South African waters with a re-description of Sepia dubia Adam et Rees, 1966. Folia Malacologica, 26(3), 125-147.

Lu, C. C. (1998a). A synopsis of sepiidae in Australian waters (Cephalopoda: Sepioidea). Smithsonian Contribution to Zoology, 586, 159-190.

Lu, C. C. (1998b). Use of the sepion in the taxonomy of Sepiidae (Cephalopoda: Sepioidea) with an emphasis on the Australian fauna. Smithsonian Contribution to Zoology, 586, 207-214.

Lu, C. C., \& Chung, W. S. (2017). Guide to the cephalopods of Taiwan. National Museum of Natural Science.

Meiri, S., \& Dayan, T. (2003). On the validity of Bergmann's rule. Journal of Biogeography, 30(3), 331-351.

Mousseau, T. A. (1997). Ectotherms follow the converse to Bergmann's rule. Evolution, 51(2), 630

Mqoqi, M., Lipiński, M. R., \& Salvanes, A. G. V. (2007). The ecology of Sepia australis (Cephalopoda: Sepiidae) along the south coast of South Africa. ICES Journal of Marine Science, 64(5), 945-955.

Neethiselvan, N., \& Venkataramani, V. K. (2010). A new species of cuttlefish, Sepia vecchioni (Cephalopoda, Sepiidae) from Colachal Coast, South India. Journal of American Science, 6(4), 12-21.

Neige, P. (2003). Spatial patterns of disparity and diversity of the Recent cuttlefishes (Cephalopoda) across the Old World. Journal of Biogeography, 30(8), 1125-1137.

Neige, P., \& Boletzky, S. (1997). Morphometrics of the shell of three Sepia species (Mollusca: Cephalopoda): Intra- and interspecific variation. Zoologische Beitraege., 38(2), 137-156.

Neige, P., Lapierre, H., \& Merle, D. (2016). New Eocene coleoid (Cephalopoda) diversity from statolith remains: Taxonomic assignation, fossil record analysis, and new data for calibrating molecular phylogenies. PLOS ONE, 11(5), e0154062.

Nesis, K. N. (1987). Cephalopods of the world. TFH Publications.

Nixon, M. (2010). Biogeography of recent forms. Treatise Online. https://doi.org/ 10.17161/to.v0i0.4084

Norman, M. D., Nabhitabhata, J., \& Lu, C. C. (2016). An updated checklist of the cephalopods of the South China Sea. Raffles Bulletin of Zoology, II, 566-592.

O'Gorman, E. J., \& Hone, D. W. E. (2012). Body size distribution of the dinosaurs. PLOS ONE, 7(12), 5e51925.

Reid, A. (2016a). Cephalopods of Australia and Sub-Antarctic territories. Cephalopods of Australia and Sub-Antarctic territories. CSIRO.

Reid, A. (2016b). Post-mortem drift in Australian cuttlefish sepions: Its effect on the interpretation of species ranges. Molluscan Research, 36(1), 9-21.

Reid, A. L. (2000). Australian cuttlefishes (Cephalopoda: Sepiidae): The "doratosepion" species complex. Invertebrate Systematics, 14(1), 1-76.

Reid, A., Jereb, P., \& Roper, C. F. E. (2005). Family Sepiidae. In P. Jereb \& C. F. E. Roper (Eds.), Cephalopods of the world. An annotated and illustrated catalogue of species known to date (Vol. 1, pp. 57-152). FAO Species Catalogue for Fishery Purposes.

Riad, R. (2015). First record of the cuttlefish Sepia dollfusi (Cephalopoda: Sepioidea) from the Egyptian Mediterranean waters. Egyptian Journal of Aquatic Biology and Fisheries, 19(3), 1-7.

Riad, R. (2020). Monograph of the egyptian octopuses order: Octopoda (Cephalopoda: Mollusca). Part III. Egyptian Journal of Aquatic Biology and Fisheries, 24(6), 73-102.

Riad, R. (2020). Taxonomical studies on the cephalopods (Cephalopoda: Mollusca) inhabiting both the Egyptian Mediterranean and the Red Sea waters. Jordan Journal of Natural History, 7, 64-92.

Roeleved, M. A. (1972). A review of the Sepiidae (Cephalopoda) of Southern Africa. Annals of the South African Museum, 59(10), 193-313.

Roeleveld, M. A., \& Liltved, W. R. (1985). A new species of Sepia (Cephalopoda: Sepiidae) from South Africa. Annals of the South African Museum, 96(1), $1-18$.

Roper, C. F. E., \& Voss, G. L. (1983). Guidelines for taxonomic descriptions of cephalopod species. Memoirs of the National Museum of Victoria, 44, 48-63.

Roper, C. F. E., Sweeney, M. J., \& Nauen, C. E. (1984). Cephalopods of the world: an annotated and illustrated catalogue of species of interest to fisheries. FAO Species Catalogue. (Vol. 3). FAO Fish Synopsis.

Rotenberry, J. T., \& Balasubramaniam, P. (2020). Connecting species' geographical distributions to environmental variables: Range maps versus observed points of occurrence. Ecography, 43(6), 897-913.

Roy, K., Jablonski, D., \& Martien, K. K. (2000). Invariant size-frequency distributions along a latitudinal gradient in marine bivalves. Proceedings of the National Academy of Sciences of the United States of America, 97(24), 13150-13155.

Smith, F. A., Payne, J. L., Heim, N. A., Balk, M. A., Finnegan, S., Kowalewski, M., et al. (2016). Body size evolution across the Geozoic. Annual Review of Earth and Planetary Sciences, 44, 523-553.

Spalding, M. D., Fox, H. E., Allen, G. R., Davidson, N., Ferdaña, Z. A., Finlayson, M., et al. (2007). Marine ecoregions of the world: A bioregionalization of coastal and shelf areas. BioScience, 57(7), 573-583.

Torres-Romero, E. J., Morales-Castilla, I., \& Olalla-Tárraga, M. (2016). Bergmann's rule in the oceans? Temperature strongly correlates with global interspecific patterns of body size in marine mammals. Global Ecology and Biogeography, 25(10), 1206-1215.

Van Voorhies, W. A. (1996). Bergmann size clines: A simple explanation for their occurrence in ectotherms. Evolution, 50(3), 1259-1264.

Vinarski, M. V. (2014). On the applicability of Bergmann's rule to ectotherms: The state of the art. Biology Bulletin Reviews, 4(3), 232-242.

Voss, G. (1974). On the absence of cuttlefish in the western Atlantic. The Veliger, 16(4), 367-369.

WoRMS Editorial Board (2021). World Register of Marine Species. http://www. marinespecies.org. Accessed 29 Jan 2021. https://doi.org/10.14284/170.

Yoshida, M., Tsuneki, K., \& Furuya, H. (2006). Phylogeny of selected Sepiidae (Mollusca, Cephalopoda) based on 12S, 16S, and COI sequences, with comments on the taxonomic reliability of several morphological characters. Zoological Science, 23(4), 341-351.

Yoshida, M., Tsuneki, K., \& Furuya, H. (2010). Molecular phylogeny among East-Asian cuttlefishes using three mitochondrial genes. In K. Tanabe, Y. 
Shigeta, \& H. Hirano (Eds.), Cephalopods_present and past (pp. 15-21). Tokai University Press.

Young, R. E., Vecchione, M., \& Donovan, D. T. (1998). The evolution of coleoid cephalopods and their present biodiversity and ecology. South African Journal of Marine Science, 20(1), 393-420.

\section{Publisher's Note}

Springer Nature remains neutral with regard to jurisdictional claims in published maps and institutional affiliations.
Submit your manuscript to a SpringerOpen ${ }^{\odot}$ journal and benefit from:

- Convenient online submission

- Rigorous peer review

- Open access: articles freely available online

- High visibility within the field

- Retaining the copyright to your article

Submit your next manuscript at $\boldsymbol{\nabla}$ springeropen.com 